\title{
AS EXPLICAÇÕES DE ERIC DUNNING SOBRE O HOOLIGANISMO À LUZ DO CONTEXTO BRASILEIRO: UMA REFLEXÃO CRÍTICA
}

\author{
ERIC DUNNING'S EXPLANATIONS ABOUT HOOLIGANISM IN THE \\ BRAZILIAN CONTEXT: A CRITICAL REVIEW
}

\section{LAS EXPLICACIONES DE ERIC DUNNING ACERCA DEL HOOLIGANISMO A LA LUZ DEL CONTEXTO BRASILEÑO: UNA REFLEXIÓN CRÍTICA}

\author{
Heloisa Helena Baldy dos Reis*, Felipe Tavares Paes Lopes**, \\ Mariana Zuaneti Martins***
}

\section{Palavras-chave}

Sociologia.

Esportes.

Violência.

Revisão.

Keywords:

Sociology.

Sports.

Violence.

Review.

Palabras clave

Sociología.

Deportes.

Violencia.

Revisión.
Resumo: A obra de Eric Dunning ocupa um papel central na conformação da área acadêmica da Sociologia do Esporte. Este artigo foi produzido a partir da leitura repetida, cuidadosa e detalhada das principais produções de Dunning e da produção científica brasileira sobre violência no futebol e/ou torcidas organizadas, dada a influência marcante desse autor nos estudos brasileiros. Para o levantamento das fontes, foram consultadas várias bases de dados, bibliotecas de universidades e nossos acervos particulares. Este estudo expõe os fundamentos da sociologia figuracional e do desenvolvimento do esporte, que criam as bases para descrevermos as explicações sobre o fenômeno do hooliganismo britânico e sua influência nas pesquisas sobre violência no futebol brasileiro.

Abstract: Eric Dunning's academic work is central in the development of sociology of sports. This article was produced after a deep, detailed and careful reading of his work and Brazilian literature concerning violence in football and/or organized fan groups (torcidas organizadas), given the author's striking influence on Brazilian studies. We consulted data from academic databases, university libraries and our personal archives. This study presents the main concepts of figurational sociology and the development of sport, which create the bases to describe explanations about British hooliganism and its influence on research about violence in Brazilian football.

Resumen: El trabajo de Eric Dunning tiene un papel central en la sociología del deporte. Este artículo fue producido a partir de la lectura cuidadosa y detallada del trabajo de Dunning y de la producción científica brasileña acerca de la violencia en el fútbol y/o las torcidas organizadas, dada la fuerte influencia de este autor en los estudios brasileños. Como fuentes, fueron consultadas varias bases de datos, bibliotecas de universidades y nuestros acervos particulares. Este estudio expone los fundamentos de la sociología figuracional y del desarrollo del deporte, que crean las bases para describir las explicaciones del fenómeno del hooliganismo británico y su influencia en las investigaciones sobre la violencia en el fútbol brasileño.
*Universidade Estadual de Campinas. Campinas, SP, Brasil. Email: heloreis14@gmail.com

**Universidade de Sorocaba.

Sorocaba, SP, Brasil.

Email: lopesftp@gmail.com

***Instituto Federal de Educação. Muzambinho. RJ, Brasil. Email: fale.com.marief@gmail.com

Recebido em: 07-07-2014 Aprovado em: 10-02-2015

(c) (1) (8) Licence 
Honrar um pensador não é elogiá-lo, nem mesmo interpretá-lo, mas discutir sua obra, mantendo-o, dessa forma, vivo, e demonstrando, em ato, que ele desafia 0 tempo e mantém sua relevância (Cornelius Castoriadis).

\section{INTRODUÇÃO}

Eric Dunning é um dos autores mais importantes e influentes da Sociologia do Esporte. Seguindo seu mestre, Norbert Elias, ele se contrapõe à ideia de que existe uma atitude natural do ser humano. Na sua perspectiva, a condição humana foi construída pelo próprio indivíduo, em um longo e demorado processo civilizatório. Em sua obra, Dunning busca discutir o esporte a partir desse processo e, ao mesmo tempo, repensar tal processo a partir dos "achados" de suas pesquisas. No Brasil, seus estudos têm servido de base analítica para diversas pesquisas em Educação Física e outros campos do conhecimento, contribuindo para definir as diretrizes dos programas e políticas públicas de esporte e lazer. Diante disto, consideramos oportuno o desenvolvimento de trabalhos que tomem suas pesquisas como objeto de investigação. Neste artigo, optamos, portanto, por (re)pensar suas explicações sobre o hooliganismo à luz do contexto brasileiro, já que sua adoção para a análise desse contexto específico enseja controvérsias teóricas e possui consequências políticas importantes.

Para atingir esse objetivo, adotamos uma estratégia argumentativa em três estágios. Num primeiro momento, apresentamos as explicações de Dunning sobre o hooliganismo. Para tanto, consideramos pertinente abordar, ainda que brevemente, as explicações sobre o tema a partir das quais e contra as quais o autor elaborou as suas. Na segunda parte, descrevemos a incorporação das referidas explicações nos estudos sobre torcidas organizadas e/ou violência no futebol brasileiro. Para tanto, buscamos material sobre o tema no Banco de Teses da CAPES, no SciELO, no levantamento de Monografia, Dissertações e Teses do Laboep, na Biblioteca da UNICAMP e no nosso arquivo particular ${ }^{1}$. Na terceira e última parte, analisamos a pertinência de tal incorporação. Mais concretamente, discutimos a pertinência das explicações de Dunning sobre o hooliganismo como ferramenta científica de análise do contexto brasileiro.

\section{AS EXPLICAÇÕES DE DUNNING SOBRE O HOOLIGANISMO}

A obra de Dunning ocupa um papel central na Sociologia do Esporte. Segundo o autor, sua dissertação de mestrado, chamada "Early Stages in the development of football as an organized game: an account of some of the sociological problems in the development of a game", de 1961, foi um dos primeiros trabalhos defendidos na Sociologia britânica que tratava especificamente do esporte (COAKLEY; DUNNING, 2000). Até aquele momento, o esporte era objeto de reflexão dos professores de Educação Física, que o discutiam como um produto cultural e social, mas ainda distante de uma discussão sociológica "com rigor e profundidade", com trabalhos ainda muito empiricistas (COAKLEY; DUNNING, 2000, p. xxiii). Na Sociologia, o esporte aparecia tangencialmente na obra de alguns autores como Theodor Adorno, Max Horkheimer e Norbert Elias, que reconheciam sua grande visibilidade, mas não o desdobravam em reflexões específicas.

$1 \mathrm{~A}$ escolha desses bancos de dados deveu-se a motivos variados. 0 site da CAPES foi escolhido porque seu banco de teses permite 0 acesso aos resumos de todas as teses e dissertações defendidas no país desde 1987. A SciELO, por sua vez, é uma biblioteca eletrônica de referência, que abrange uma vasta coleção de periódicos científicos brasileiros. O levantamento do Laboep disponibiliza diversas monografias, dissertações e teses sobre torcidas de futebol. Já a biblioteca da UNICAMP é de referência, oferecendo um grande acervo de livros - um importante tipo de produção não disponibilizado pelos bancos de dados anteriores. Finalmente, nosso arquivo particular possui algumas produções não encontradas em qualquer outro lugar. 
Entre outros assuntos relativos ao esporte, Dunning se debruçou sobre o hooliganismo. Este fenômeno ganhou notoriedade na década de 1960, notabilizando-se como um grave problema social britânico. Na década de 1980, tal fenômeno ganhou uma dimensão pública ainda maior, devido, entre outras razões, a algumas tragédias de grandes proporções - ainda que, em alguns casos, essas tragédias tenham sido erroneamente atribuídas às ações dos hooligans, como a de Hillsborough, quando 96 torcedores do Liverpool morreram pisoteados ou comprimidos contra o alambrado, por conta da superlotação e da incompetência policial. Devido ao aumento do interesse pelo hooliganismo, Dunning e seus colegas de Leicester tais como Patrick Murphy, Ivan Waddington e John Williams - receberam, na década de 1980, fundos substanciais do Conselho de Pesquisas em Ciências Sociais (Social Science Research Council) e do Football Trust.

Embora exercessem certa hegemonia em tal década, esses autores não foram os pioneiros na realização de estudos sobre violência no futebol nem na Grã-Bretanha nem fora dela. Outros trabalhos já vinham sendo desenvolvidos, como era o caso, por exemplo, daqueles levados a cabo pelo sociólogo alemão Gunter A. Pilz (HOLLANDA, 2008). No contexto britânico, dois conjuntos de explicações se destacavam no âmbito acadêmico: as psicossociológicas, fornecidas pelos pesquisadores de Oxford Peter Marsh, Elisabeth Rosser e Rom Harré e as sociológicas, de base marxista, fornecidas por lan Taylor e John Clarke (MURPHY; WILLIANS; DUNNING, 1994). Essas explicações foram objeto de discussão de Dunning, Murphy e Willians, assim como algumas explicações "oficiais", que gozavam (ao menos até final da década de 1980) de ampla aceitação das autoridades ligadas ao futebol. Entre essas explicações, a que afirma que o principal "vilão" da violência no futebol é o consumo de álcool e a que sustenta que essa violência seria o reflexo da violência ocorrida no campo de jogo (DUNNING; MURPHY; WILLIANS, 1993, MURPHY; WILLIANS; DUNNING, 1994).

Em relação às explicações "oficiais", Dunning, Murphy e Willians (1993) consideram que elas apresentam limitações analíticas. Afinal, há torcedores violentos que não bebem ${ }^{2}$ e torcedores pacíficos que bebem muito. Do mesmo modo, há partidas em que há violência dentro do campo, mas não há na arquibancada e vice-versa. Além do mais, muitas das brigas ocorrem antes das partidas. Ao sustentarem que essas explicações possuem limitações analíticas, tais autores não negam, no entanto, que o consumo de álcool e que violência dentro do campo de jogo possam, em determinados momentos, facilitar a violência entre torcedores. $\mathrm{Na}$ verdade, eles chamam a atenção para o fato de que tais explicações devem ser inseridas em um marco explicativo mais amplo. Por exemplo, seria preciso compreender o papel que 0 consumo (excessivo) de álcool e a violência cumprem dentro do modelo de masculinidade que orienta os torcedores mais violentos.

Em relação às explicações fornecidas pelos pesquisadores de Oxford, Dunning, Murphy e Willians (1993) observam, entre outras coisas, que eles subestimaram a gravidade da violência entre torcedores rivais. De acordo com os pesquisadores de Leicester, isto se deve ao fato de os primeiros considerarem que a violência dos hooligans limita-se, em geral, ao plano simbólico, ou seja, a ameaças exageradas, a insultos ritualizados e a negação da masculinidade do adversário. Tal limitação dever-se-ia, em parte, ao fato de os pesquisadores de Oxford terem sido bastante influenciados pela obra do etnólogo Desmond Morris e, consequentemente, pressuporem que ritual e violência são mutuamente excludentes como 
categoria de comportamento - o que os teria "cegado" para o fato de os ritos poderem ser seriamente violentos. Outra crítica feita aos pesquisadores de Oxford é que eles, embora tenham demonstrado que a violência no futebol seja governada por uma série de regras, não teriam indicado como essas regras são socialmente construídas, criando a impressão de que elas são criações voluntárias de indivíduos que agem livremente, sem "correntes sociais".

Em relação às explicações fornecidas por Taylor e Clarke, Dunning, Murphy e Willians (1994) destacam que, grosso modo, ambos os autores analisaram o hooliganismo como uma espécie de "movimento de resistência" de jovens da classe trabalhadora ao processo de mercantilização do futebol britânico. Embora não neguem totalmente a validade dos resultados dos trabalhos de Taylor e Clarke, eles os criticam porque levariam a crer que a violência no futebol surgiu, como fenômeno social, nos anos 1960. Outra crítica feita é que tais explicações sugeririam um conflito bem definido entre grupos pertencentes à classe trabalhadora e "[...] que os participantes mais natos se enfrentam com as autoridades e com os membros das classes mais estabelecidas em grande medida como parte de uma tentativa de brigar entre eles mesmos (DUNNING; MURPHY; WILLIANS, 1993, p. 304, tradução nossa, grifos dos autores).

Em resposta a essas explicações, Dunning, Murphy e Willians (1993) analisaram 0 hooliganismo a partir da teoria do processo civilizatório. Em seus dois volumes sobre o referido processo, Elias e Dunning (1992) descrevem, a partir de um estudo minucioso de fontes sobre os comportamentos e normas sociais das sociedades inglesa, francesa e alemã dos séculos XII ao XIX, uma série de mudanças sociais. Entre outras mudanças, destaca o desenvolvimento de uma maior elaboração de refinamentos de padrões sociais; 0 aumento da pressão social para o exercício do autocontrole ${ }^{3}$ dos sentimentos, comportamentos e funções corporais; e a ampliação do controle da violência e das agressões. Ampliação que, segundo ele, produziu a diminuição da capacidade de sentir prazer em causar sofrimento e testemunhar violência e pelo aumento da identificação mútua. Essas mudanças, contudo, longe de possuírem uma relação linear de causa e efeito, formariam um mesmo processo social. Mais exatamente, um processo cego, não planejado e que não possui uma direção específica. Isto significa que, na medida em que ele é fruto de transferências geracionais de experiências e saberes, também está sujeito a processos reversos, ou seja, a "explosões descivilizadoras" (DUNNING, 2014).

"Explosões" que, para Dunning, Murphy e Willians (1993), explicariam o hooliganismo. Este seria gerado pela não incorporação dos segmentos "rudes" da classe trabalhadora inglesa dos valores e modos de conduta mais "civilizados". Os jovens oriundos desses segmentos encontrariam, no contexto do futebol, um espaço privilegiado para brigas, agressões e outras formas de violência ${ }^{4}$ - que, no seu meio social, serviriam como um meio de afirmação pública de masculinidade. Diferentemente do que ocorreria nas classes sociais mais "estabelecidas", a prática da violência nesses segmentos não seria necessariamente motivo de vergonha. Pelo contrário, ela seria mais aberta, tolerada e, até mesmo, motivo de orgulho, já que aos seus integrantes seriam "[...] negados invariavelmente o status, o significado e a gratificação nas esferas educativa e ocupacional, as principais fontes de identidade, sentido e status de que dispõem os homens para subir na escala social" (DUNNING; MURPHY; WILLIANS, 1993, p. 258, tradução nossa).

3 Autocontrole pode ser entendido como aumento da capacidade da consciência como reguladora do comportamento, agindo como controladora dos impulsos e pulsões dos seres humanos, em direção à adaptação aos padrões sociais de comportamentos (ELIAS; DUNNING, 1992). 
Os adultos dos referidos segmentos também teriam menos controle sobre as crianças e adolescentes, já que estes passariam boa parte do tempo nas ruas, socializando com outras crianças e adolescentes mais velhos. Consequentemente, a interação entre eles se daria de forma agressiva, desenvolvendo hierarquias de domínio baseadas, em grande medida, na idade, na força física e na coragem (DUNNING; MURPHY; WILLIANS, 1993). Diante disto, Dunning, Murphy e Willians (1993, p. 259, tradução nossa) sustentam que esses jovens:

[...] por um lado, tendem racionalmente a buscar confrontos físicos porque estes representam para eles uma fonte de identidade, posição, sentido e excitação prazerosa. Por outro, tendem a responder agressivamente em situações ameaçadoras porque aprenderam a não exercer o grau de autocontrole que demandam as normas dominantes na sociedade britânica.

De acordo com esses autores, a partir de meados dos anos 1960, esses jovens sentiram-se ainda mais motivados a causar distúrbios e confusão no futebol porque os periódicos ingleses começaram a veicular com maior frequência matérias sobre desordens nos estádios, como locais dominados por vândalos. Análise que influenciará, até certo ponto, a produção científica brasileira sobre torcidas organizadas e/ou violência no futebol.

\section{A INCORPORAÇÃO DAS EXPLICAÇÕES DE DUNNING SOBRE O HOOLIGANISMO NOS ESTUDOS SOBRE TORCIDAS ORGANIZADAS E/OU VIOLÊNCIA NO FUTEBOL BRASILEIRO}

A análise da referida produção nos indica que a obra de Dunning é citada com frequência, servindo de subsídio teórico para alguns pesquisadores brasileiros contextualizarem a violência no futebol. No campo da Sociologia do Esporte, temos como exemplo disto o livro Futebol e Violência, de Reis (2006). Já no campo da História e no da Psicologia, encontram-se teses de doutorado (HOLLANDA, 2008, LOPES, 2012) que tratam, em alguma medida, do debate acadêmico em torno das teses da Escola de Leicester, apresentando algumas críticas feitas a elas. Todavia, embora tenha recebido certa atenção dos pesquisadores brasileiros, notamos que a incorporação da obra de Dunning varia significativamente conforme o campo de estudo.

No campo da Psicologia, por exemplo, sua influência é bem limitada. Prova disto é que nenhum dos principais trabalhos realizados nessa área sobre torcidas organizadas e/ ou violência no futebol (LUCCAS, 1998, CAVALCANTI, 2002, CARNEIRO; SANTOS, 2008; HRYNIEWICZ, 2008, SANTOS, M. B., 2009, LOPES; CORDEIRO, 2010, LOPES, 2012, 2013, ARAGÃO, 2013) é norteado pelo "paradigma figuracional". Aliás, em alguns desses trabalhos, Dunning sequer é citado. Uma rara exceção é a tese de Lopes (2012), que, ainda que parta de outro referencial, discute algumas das teses da Escola de Leicester e as críticas feitas a elas. Num primeiro momento, poderíamos atribuir essa falta de influência ao fato de Dunning não ser psicólogo. Essa explicação, todavia, parece ser pouco plausível, pois a maioria dos autores supracitados atua na área da Psicologia Social, campo que tradicionalmente dialoga com a Sociologia. Uma explicação mais adequada é que, dado que a temática do esporte está pouco presente no campo da Psicologia, consagrados sociólogos da área ainda são pouco trabalhados e, até mesmo, conhecidos. Outra explicação possível é que, no Brasil, o campo de estudos sobre violência no futebol ainda é bastante fragmentado, dificultando o diálogo entre as diferentes áreas do conhecimento. 
Por sua vez, no campo da Antropologia, parte significativa dos estudos sobre torcidas organizadas e/ou violência no futebol dialoga, em algum momento, com a obra de Dunning e com a de Elias. Exemplo disso são os trabalhos pioneiros de Toledo (1996) e de Teixeira (2004). Em Os perigos da paixão, Teixeira (2004, p. 173) estuda, através da observação etnográfica, o universo das torcidas organizadas dos grandes clubes do futebol carioca e afirma, corroborando as reflexões de Elias, que "parece particularmente boa a concepção de que um jogo de futebol, mais do que um passatempo ou divertimento, seja uma forma de excitação em que os espectadores simulam embates, liberando com moderação, certas emoções". Partindo, então, do pressuposto de que o futebol simula embates, a autora levanta a seguinte questão: por que essas simulações, às vezes, convertem-se em embates concretos? Para respondê-la recorre novamente à obra de Elias e observa que

\begin{abstract}
a função compensadora da excitação através do jogo aumenta na medida em que as inclinações sérias e ameaçadoras diminuem. Isso significa que o esporte se constitui numa espécie de antídoto ao excesso de controle e tensões dos indivíduos, fazendo-os liberar moderadamente as emoções", contudo, essas excitações provenientes de tensões miméticas, podem converter-se em sérias e gerar "jatos de descivilização" (TEIXEIRA, 2004, p. 171-172, grifo da autora).
\end{abstract}

No campo da Sociologia do Esporte, as obras de Elias e de Dunning são igualmente influentes. Esse campo, contudo, possui uma diferença em relação aos demais: apenas parte dos estudos sociológicos sobre violência no futebol e/ou sobre torcidas organizadas que dialogam com as referidas obras foram produzidos dentro de departamentos de Sociologia. Entre aqueles estudos que foram produzidos em tais departamentos, destacamos a dissertação de mestrado de Monteiro (2003), que, entre outras coisas, problematiza a pertinência de, no contexto carioca, relacionar um ideal mais "agressivo" de masculinidade com os setores mais "rudes" da classe trabalhadora, como fazem Dunning e Elias na Inglaterra. Para o autor, o "etos guerreiro" e o "ideal de macho" se manifestam, também, nas classes média e média alta, com acesso a ensino privado de qualidade e a bens de consumo de alto valor.

Já no departamento de Ciências Sociais Aplicadas da Universidade Estadual de Ponta Grossa, o estudo de Netto (2009) utiliza as noções de psicogênese e de sociogênese de Elias para compreender o fenômeno das torcidas organizadas e suas relações com a violência. Por sua vez, no campo da Educação Física, Heloisa Reis tem levado a cabo uma série de pesquisas sobre violência no futebol que dialogam com obra de Dunning - algumas delas desenvolvidas por seus orientados, como a dissertação de mestrado de Canale (2012). Na sua tese de doutorado (REIS, 1998), a autora utiliza-se da tipologia da ação de Weber, aperfeiçoada por Dunning, para tratar dos incidentes de violência. Outro conceito central retirado da obra de Dunning e de Elias apresentado por Reis (1998) é o de "ligações sociais". Além de apoiar-se na Escola de Leicester para desenvolver suas pesquisas, Reis organizou a $1^{\mathrm{a}}$ e a $10^{\mathrm{a}}$ edição do Simpósio Internacional sobre Norbert Elias e o Processo Civilizador, na Universidade Estadual de Campinas, bem como a $1^{\underline{a}}$ e a $2^{\underline{a}}$ edição do Seminário Hooliganismo e Copa do Mundo de 20145. 0 1․ Seminário contou com a participação de Dunning, que, posteriormente, foi transformada em um capítulo do livro Sociologia do esporte e os processos civilizatórios, publicado em 2014.

5 Segundo Reis (2014), Eric Dunning já esteve no Brasil oito vezes, contribuindo com o debate sobre violência no esporte. A FEF Unicamp tem sido um dos núcleos receptores e difusores da obra dele no Brasil. Na sua última visita, ele produziu um livro exclusivamente ao público brasileiro, intitulado Sociologia do esporte e os processos civilizatórios, fornecendo detalhamentos teóricos sobre a teoria dos processos civilizatórios e seus desdobramentos para a análise do fenômeno esportivo e da violência (DUNNING, 2014). 


\section{CONTRIBUIÇÕES E LIMITES DAS EXPLICAÇÕES DE DUNNING SOBRE 0 HOOLIGANISMO PARA A COMPREENSÃO DO CONTEXTO BRASILEIRO}

É importante notar que o título do evento anteriormente citado leva o termo "hooliganismo", remetendo-se a uma das hipóteses levantadas pelo autor de que este seria um fenômeno mundial. Tal problemática se coloca como uma questão polêmica no atual debate sobre violência no futebol brasileiro: a existência ou não de hooligans brasileiros. No clássico Fighting Fans, Dunning et al. (2002) argumentam que o hooliganismo é um fenômeno mundial. Tal livro é estruturado em 16 capítulos, onde notórios pesquisadores escrevem sobre a violência no futebol em diferentes países. Já no capítulo introdutório, Dunning et al. (2002) observam que o termo hooliganismo é impreciso, pouco científico e que ele cobre uma vasta variedade de comportamentos que estão, até certo ponto, relacionados ao futebol. Também explicam que, ao utilizarem esse termo para entender esses comportamentos em outros países, não significa que eles entendam que o hooliganismo seja, sempre e em todo lugar, explicado principal ou unicamente pela questão de classe.

Em El fenómeno deportivo, Dunning (2003) faz outra ressalva importante: para ele, a ideia de que o hooliganismo é um fenômeno mundial não passa de uma hipótese de trabalho. Para que ela seja confirmada, seria preciso submetê-la a um debate público e, sobretudo, ser provada mediante estudos empíricos, sistemáticos, baseados em uma teoria e desenvolvidos em diferentes partes do mundo. Esse trabalho, todavia, como reconhece o próprio autor, seria muito custoso e difícil de organizar, dada a falta atual de uma unidade paradigmática na Sociologia. No entanto, apenas por meio dele poder-se-ia se modificar, revisar e expandir a hipótese de que o hooliganismo é um fenômeno mundial - ou, até mesmo, descartá-la completamente.

No contexto sul-americano, alguns pesquisadores se recusam a utilizar a categoria hooligan. No próprio livro Fighting Fans, no capítulo 'Aguante' and repression: football, politics and violence in Argentina, o sociólogo Pablo Alabarces (2002) esclarece que, do seu ponto de vista, existem diferenças significativas entre os barras-bravas ${ }^{6}$ argentinos e os hooligans britânicos. A principal delas seria o fato de os primeiros estarem historicamente relacionados com a violência política. De acordo com o autor, não teria sido à toa que o fim da ditadura argentina, em 1983, combinou com o "reaparecimento explosivo" das barras. No livro Crónicas del aguante, ele explicita o argumento: "[...] as barras copiaram o modelo das forças-tarefas da ditadura e atuam por fora do monopólio legítimo da violência estatal, base do contrato liberal da modernidade. Tal contrato foi violado total e completamente pelos militares" (ALABARCES, 2012, p. 35). Hoje em dia, segue o autor (ALABARCES, 2012), muitos desses grupos atuam como força de choque a serviço de dirigentes esportivos e políticos, que os financiam.

Certamente, a adoção por parte das barras de um modelo nativo de organização e operação parece fazer com que os conflitos na Argentina tenham algumas características próprias. Por exemplo, atualmente, o maior número de homicídios no futebol local deve-se a disputas internas nesses grupos (SUSTAS, 2011), provocadas, entre outras coisas, pelo controle do mercado ilegal da (re)venda de ingressos. Mercado que existe graças à relação anteriormente citada entre as lideranças das barras e os dirigentes esportivos. Além de alguns

6 Aqui cabe um esclarecimento: a categoria barras-bravas não é nativa, ou seja, ela não é utilizada pelos integrantes desses grupos, que chamam a si mesmos de la hinchada. Trata-se de uma categoria pejorativa utilizada pelos meios de comunicação e por outros torcedores, que acusam tais integrantes de terem uma relação instrumental com o clube, que seria motivada por um interesse particular e econômico - 0 que, evidentemente, é negado pelos últimos (ALABARCES, 2012). 
conflitos apresentarem características próprias, alguns deles envolvem o uso de armas de fogo - coisa rara no contexto inglês. No entanto, apesar disso, esses conflitos (ao menos parte significativa deles) estão, conforme nos sugerem as análises de Zucal (2010), intimamente associados a um determinado padrão de masculinidade. Mais concretamente, com o princípio do aguante, que determina que, para ser "homem de verdade", é preciso tolerar a dor física.

Embora Zucal (2010) e Alabarces (2012) rejeitem algumas das teses da Escola de Leicester, difícil não notar aqui certa semelhança com a "masculinidade agressiva" de que fala Dunning. Em El fenômeno desportivo, Dunning (1999) reconhece que podem existir diferenças entre os ideais hispânicos de machismo e os ideais masculinos do Norte da Europa e da América do Norte. No entanto, ele observa que existe uma característica geral do patriarcado: o pressuposto de que os homens lutarão e se mostrarão agressivos em situações específicas, como para defender a honra da pátria numa guerra. Assim, dado que o futebol seria a pantomima desta última, ele facilitaria a manifestação do comportamento bélico do patriarcado. Neste sentido, a própria estrutura do futebol de elite mundial, combinada com as características gerais do patriarcado, ajudaria a criar desordens e violência constante - o que faria do hooliganismo um fenômeno mundial. Além do mais, Dunning (1999) observa que o núcleo duro dos torcedores violentos agiria de forma premeditada.

Por essa razão, talvez fosse possível falar em hooliganismo no Brasil. Falar em hooliganismo no Brasil, todavia, não significa afirmar que os nossos torcedores organizados sejam os equivalentes dos hooligans britânicos. Essa tese é refutada pela grande maioria dos estudiosos do tema (TOLEDO, 1996, PIMENTA, 1997, REIS, 1998, SANTOS, T. C., 2004, LOPES; CORDEIRO, 2010, LOPES, 2012), que indicam que existem diferenças significativas entre ambos os grupos. Inclusive, conforme destaca Murad (2007, 2012), apenas uma minoria dos torcedores organizados (entre 5 e 7\%) se envolvem em ações violentas. Diante disto, a questão levantada é se os torcedores violentos brasileiros - integrantes ou não de torcidas organizadas - podem ser categorizados como hooligans.

A primeira dificuldade em categorizá-los dessa forma é justamente a falta de consenso acerca da própria definição de hooliganismo ${ }^{7}$. O que vem a ser exatamente tal forma de ação? Essa dificuldade, todavia, não parece ser uma barreira intransponível, pois, ainda que não haja consenso em torno dessa definição, bastaria explicitar e justificar a utilizada. No entanto, não podemos esquecer que a referida categoria foi criada por políticos e jornalistas e, apenas posteriormente, incorporada pelo campo científico (DUNNING, 2014). Assim, a pergunta que segue é: até que ponto é pertinente tal campo fazer uso de uma categoria que carrega uma carga valorativa (negativa) e que frequentemente reforça estereótipos e alimenta preconceitos? Não seria mais adequado fazer uso de categorias utilizadas pelos "nativos"8? Longe de ser um preciosismo acadêmico, considerar a perspectiva dos "de dentro", daqueles que participam dos embates corporais e armados no futebol brasileiro, tem consequências importantes. A principal delas é que quebramos com o mito - muito difundido pelos meios de comunicação e pelo "senso comum" - de que a violência provocada e sofrida por esses atores seja irracional. Pelo contrário, conforme observa Toledo (2012, p. 140), é possível supor que ela tenha a ver com o descomprometimento com o corpo reificado historicamente pela moralidade do trabalho, isto é,

7 Termo criado e utilizado primeiramente por jornalistas britânicos.

8 No Brasil, o torcedor que se envolve em embates corporais é usualmente chamado de "pista". Uma torcida que vai para a "pista" é uma torcida vai para o confronto. 
ela estaria relacionada c ${ }^{9}$ om a projeção, a partir dos anos 1990, de "[...] outras possibilidades de ascensão social ou visibilidade para além do valor centrado no esforço do valor manual, na moralidade em torno da família ou da religião".

Outra dificuldade com a adoção da categoria hooligan é que a violência no futebol brasileiro tem singularidades. Por exemplo, o uso de armas de fogo é muito mais difundido aqui do que na Inglaterra ${ }^{10}$ - o que eleva, e muito, a taxa de mortalidade. Além disso, no Brasil, parece ser mais raro o envolvimento de torcedores violentos com partidos de extrema direita e/ou com projetos nacionalista ${ }^{11}$ (LOPES; CORDEIRO, 2010). Isto sem falar na emergência no país, a partir de 2005 , de conflitos de torcedores do mesmo grupo em função do tráfico de drogas e de armas (MURAD, 2007).

Diante destas e de outras diferenças entre os torcedores violentos brasileiros e britânicos, talvez seja o caso de entender o hooliganismo apenas como uma forma de posicionamento dos torcedores violentos, que vai depender das normas sociais que regulam as interações entre eles em situações específicas (DAVIES; HARRÉ, 1999). Assumir a ideia de posicionamento implicaria, portanto, aceitar que esses torcedores podem se posicionar (e serem posicionados) ou não como hooligans nos embates violentos. Trabalhar com essa noção também ajudaria a desfazer alguns mal-entendidos, como 0 de que um torcedor classificado como hooligan se comportará da mesma maneira em todos os eventos de futebol. Recordemos que muitos integrantes da torcida nacional escocesa - o Tartan Army - comportam-se de forma pacífica nos jogos de sua seleção - sobretudo, no exterior. Todavia, operam como hooligans violentos no âmbito clubístico dentro de seu país (GIULIANOTTI, 2002).

No entanto, mais do que com a categoria hooliganismo em si, nossa preocupação maior diz respeito aos usos políticos e ideológicos que se tem feito dela. A linguagem, como se sabe, não é uma representação neutra da realidade, uma mera roupagem que colocamos sobre nossas ideias para poder expressá-las, mas é construtora do mundo em que vivemos, podendo tanto reproduzi-lo quanto transformá-lo (IBAÑEZ, 2005). No contexto brasileiro, o termo hooliganismo tem servido para legitimar a adoção do "modelo britânico" de segurança (e isso, como veremos, tem implicações negativas). A lógica apresentada é simples: violência no futebol é sinônimo de hooliganismo. O Reino Unido eliminou o hooliganismo. Logo, devemos adotar as soluções tomadas lá. Essa lógica está presente, por exemplo, no relatório, de 2005/2006, da Comissão Nacional de Prevenção da Violência para a Segurança dos Espetáculos Esportivos (CONSEGUE), do Ministério do Esporte e do Ministério da Justiça, que serve de base para uma série de experiências, a título de projeto-piloto, em partidas realizadas no estado de São Paulo. ${ }^{12}$

Evidentemente que reconhecemos que lições vindas de fora devem ser assimiladas. Todavia, não podemos perder de vista que elas precisam ser adaptadas. Assim, o "modelo britânico" não pode ser tomado de forma acrítica, como faz o relatório da CONSEGUE. Seguindo

\footnotetext{
9 Embora ele nem sempre seja visto como legítimo. No contexto argentino, a antropóloga Verónica Moreira (2013) faz uma interessante análise das disputas morais em torno do uso da arma de fogo no futebol.

10 Embora ele nem sempre seja visto como legítimo. No contexto argentino, a antropóloga Verónica Moreira (2013) faz uma interessante análise das disputas morais em torno do uso da arma de fogo no futebol.

11 Embora seja preciso ressaltar que, de acordo com Giulianotti (2002), a mídia, em geral, sobre-estima essa relação no Reino Unido. Ligações com a extrema-direita seriam típicas sim dos grupos skinhead alemães e holandeses (ALABARCES, 2012).

12 LOPES, Felipe Tavares Paes; REIS, Heloisa Helena Baldy dos. Políticas de segurança ou de dominação? Dimensões ideológicas do relatório da comissão paz no esporte. s.n.t. (Mimeo).
} 
as reflexões de Lopes e Reis ${ }^{13}$, não podemos deixar de perceber uma série de problemas com tal modelo. Além de não ter conseguido acabar com o hooliganismo (hoje ele ocorre nos pubs, nos trajetos para o exterior e nas divisões inferiores), ele contribuiu para a elitização e pasteurização do futebol britânico. Conforme observa Giulianotti (2002, p. 109), atualmente, "[...] os seguranças expulsam aqueles que se levantam e obstruem a visão dos outros. Os torcedores que gritam nas partidas de futebol podem ser acusados de transgredir a ordem pública de acordo com a legislação recente". Além disto, apenas com base nas informações do serviço de inteligência, um torcedor pode ser considerado um hooligan potencial e ser impedido de entrar nos estádios, mesmo na ausência de qualquer condenação prévia. Com isso, o "modelo britânico" inverte a lógica do direito penal, descartando o princípio de presunção de inocência em favor de uma verdadeira pressuposição de culpa (TSOUKALA, 2014).

Sendo assim, cabe a pergunta: será que é isso que queremos para o Brasil? Devemos sacrificar uma cultura popular de torcer em nome de um modelo de segurança controverso? Dunning e colaboradores (DUNNING; MURPHY; WILLIANS, 1993) costumavam dizer que o futebol é uma área reservada masculina. Certamente, a partir dos anos 1990, ele se transformou, no Reino Unido, em uma área reservada para as classes média e alta. Diante disto, não seria o caso de considerarmos nossas singularidades e olharmos com mais atenção para projetos desenvolvidos em realidades mais próximas da nossa, como a colombiana?

A preocupação com os usos políticos e ideológicos das teses de Dunning também está presente nas reflexões de Zucal (2010) e Alabarces (2012), principalmente a vinculação feita entre classe social e hooliganismo. Apoiados nas análises de Armstrong e Giulianotti, os autores sustentam que a relação estabelecida pelo pesquisador de Leicester entre hooliganismo e os setores "rudes" da classe trabalhadora inglesa contribuiu para legitimar ações repressivas sobretudo, frente a tais setores. Para eles, não foi à toa que a Escola de Leicester recebeu muitos recursos justamente durante o governo de Margareth Thatcher, para quem "[...] a culpa de tudo tinham e têm os pobres..." (ALABARCES, 2012, p. 135, tradução nossa). Ainda que as teses de Dunning possam, de fato, ter sido funcionais para as políticas repressivas de Thatcher, é preciso, contudo, reconhecer que o autor guarda uma série de ressalvas em relação a elas. Em O futebol no banco dos réus, Murphy, Williams e Dunning (1994, p. 218) são enfáticos:

[...] o encarceramento na sua forma atual, e como resposta genérica ao hooliganismo, tem a mesma credibilidade científica de que o álcool é uma boa cura para ressaca. Por outro lado, a abordagem punitiva tem como finalidade a dissuasão, isto é, pretende evitar que mais gente adira às fileiras do hooliganismo. No entanto, os acontecimentos das últimas décadas não dão a entender que os grupos de hooligans tenham sentido quaisquer dificuldades de recrutamento.

Outra crítica feita por Zucal (2010) e Alabarces (2012) a Dunning é que, atualmente, existe uma participação da classe média nas barras argentinas, como é o caso dos patovicas, núcleo duro da barra Los Borrachos del Tablón, do River Plate. Ou seja, a composição social das barras seria relativamente heterogênea. Armstrong (2003), em suas pesquisas de campo na cidade de Sheffield, tinha chegado a conclusões semelhantes em relação aos hooligans locais. Infelizmente, não há espaço aqui para discutirmos o debate metodológico por detrás dessa discussão. No entanto, para nossos fins, basta destacar que a questão de classe, a princípio, é vista como central para o debate sob análise. 
Certamente, 0 debate sobre violência no futebol e classe social enseja reflexões importantes. Em primeiro lugar, a de que não existe uma única definição de classe social. Pelo contrário, assiste-se, no interior do campo científico, a uma luta social pela definição legítima de classe. Assim, evidentemente, consideramos que não é possível relacionar violência e classe social sem, antes, definir, com clareza, este último conceito (o que, evidentemente, pressupõe uma teoria de sociedade bem definida). Ocorre que, no debate acadêmico sobre violência no futebol brasileiro, isto quase nunca é feito. Inclusive, algumas críticas feitas ao Dunning pelo emprego do termo "setores 'rudes' da classe trabalhadora" parecem ignorar a definição exata dada por ele.

Em resposta aos seus críticos britânicos, Dunning (2006) destaca que o termo "rude" (tradução nossa do inglês roughness) é definido apenas em termos de valores relacionados à violência e iniciação de lutas. Valores que seriam compartilhados por grupos que possuem algumas ou todas essas características: pobreza mais ou menos extrema; trabalhos não especializados e/ou instáveis; baixo nível educacional formal; baixa mobilidade geográfica; uma família de grande rede de parentesco, mas centrada na mãe; e alta segregação social dos papéis sociais de gênero, com predomínio do poder do homem sobre a mulher, frequentemente exercido violenta e fisicamente (ELIAS; DUNNING, 1992). Como essas características se relacionam de forma complexa e indireta, e como nem todas elas precisam estar presentes para um grupo ser "rude", não nos parece correto afirmar que Dunning estabelece uma relação, mecânica e preconceituosa, entre pobreza e violência. Afinal, ele abre espaço para pensarmos que a primeira não é condição necessária para a segunda. Pelo contrário, chama a atenção para o fato de que muitos pobres são "respeitáveis" e de que a classes média e alta também possuem seus setores "rudes". Inclusive, reconhece que uma parte (em torno de 20 a $30 \%$ ) dos hooligans provém destas últimas (DUNNING, 2006).

Ao comentar a violência no futebol em outras regiões do mundo, Dunning $(2003,2006)$, inclusive, afirma que o que une os torcedores violentos não é, necessariamente, a classe social. Por isso mesmo, para evitar mal-entendidos e não dar a impressão de que suas análises são universais, o autor faz mea-culpa e observa que seu clássico The roots of football hooliganism, escrito em parceria com Murphy e Willians, deveria ter seu título alterado para The roots of English football hooliganism. Do seu ponto de vista, portanto, o que realmente é universal é a violência no futebol. Violência que seria desenhada e alimentada pelas fault lines de cada país. $\mathrm{Na}$ Inglaterra, pela desigualdade entre as classes sociais e entre regiões. Na Escócia (ao menos em Glasgow) e Irlanda do Norte, pelo sectarismo religioso. Na Espanha, pelo nacionalismo linguístico de catalães, castelhanos, bascos e galeses. Na Itália, pelas divisões entre Norte e Sul. Na Alemanha, pelas relações entre Leste e Oeste e entre grupos de direita e esquerda. De acordo com Dunning, essas fault lines, frequentemente, se sobrepõem e se alimentam mutuamente. Assim, quando ele afirma que na Escócia e Irlanda do Norte a questão religiosa é central, ele não quer dizer que lá a questão de classe não exista e que ela não tenha relação com a primeira, apenas que, possivelmente, seu "peso" na produção da violência seja menor.

Feito esse esclarecimento, Dunning $(2003,2006)$ observa que, a título de hipótese ${ }^{14}$, é possível supor que exista algo de comum entre todas essas fault lines: o fato de elas estarem sujeitas a produzirem aproximações estruturais em relação à chamada "segmentação ordenada" ou, para expressá-la com termos eliasianos, figurações sociais de "estabelecidos-outsiders".

14 Hipótese que, segundo Dunning (2006), deve ser "testada" por uma série de pesquisas empíricas e teoricamente orientadas, que pode modificá-la, revisá-la ou expandi-la. 
Figurações que seriam organizadas através de laços grupais que fazem surgir um antagonismo intenso do "nosso grupo" contra o "grupo dos outros". O hooliganismo, enquanto fenômeno mundial, seria, portanto, estruturado por conflitos ensejados por esse tipo de figuração social. Esta, cabe observar, não seria a "causa" do hooliganismo, mas desempenharia certo papel na sociogênese e reprodução dos grupos mais violentos, sendo gerada, reforçada e reproduzida no interior das sociedades patriarcais.

Outra possível crítica a Dunning (e sua pertinência ou não para o contexto brasileiro) que cabe ser analisada é a de que ele reduz a violência no futebol às ações dos hooligans, esquecendo-se das promovidas por outros atores sociais. Por um lado, Dunning (1994) enfatiza o papel central que os meios de comunicação desempenharam na promoção do hooliganismo - em especial, a partir dos anos sessenta. Como já vimos, ele também critica a repressão policial e muitas das medidas adotadas pelas autoridades britânicas. Diante disto, parece-nos incorreto acusá-lo de reduzir o problema à ação dos hooligans. Por outro lado, sua obra parece não dar suficiente destaque ao fato de que, frequentemente, a violência é legitimada (o que não significa que ela seja legal) também fora dos círculos dos torcedores violentos. Evidentemente, esse tipo de dado não pode ser obtido através de nenhuma enquete (ALABARCES, 2012; ZUCAL, 2010), já que a maior parte dos torcedores está consciente de que as normas e valores gerais condenam a prática da violência. No entanto, a legitimação dessa prática se torna evidente ao investigar o contexto imediato das partidas de futebol no Brasil. Por exemplo, ameaças contra atletas e torcedores adversários podem ser escutadas em todos os setores dos estádios brasileiros, sem exceção.

Por último, cabe observar que sua obra tampouco parece dar o devido destaque ao processo político de produção das políticas de prevenção da violência no futebol, limitando-se à análise do "produto final". Ainda que esse tema seja complexo e enseje questões que não possam ser unificadas facilmente - tais como exclusão social, democracia, violência e justiça social -, ele não pode ser apartado da análise da violência no futebol brasileiro. Em primeiro lugar, porque ela possui efeitos sobre os próprios índices de violência e criminalidade. Afinal, o não reconhecimento dos direitos democráticos dos torcedores e sua exclusão do referido processo tendem a fazer com que toda norma seja vista como uma forma de repressão e, consequentemente, como um convite à repressão. Em segundo lugar, porque, se assumimos um conceito mais ampliado de violência, essa exclusão pode ser interpretada como uma forma de violência estrutural, que destrói os laços solidários e produz sofrimento psíquico. Como diria Vasilachis de Gialdino (2004, p. 111), "[...] é mister recordar que dói tanto a ferida como 0 desprezo, a chicotada como a indiferença" .

\section{CONSIDERAÇÕES FINAIS}

Neste texto, buscamos (re)pensar as explicações de Dunning sobre o hooliganismo à luz do contexto brasileiro. Com isso, buscamos problematizar tanto sua adoção automática, feita sem nenhuma mediação histórica e social, quanto sua simples rejeição. E, ao problematizar isso, buscamos indicar em que medida seu enfoque pode ser construtivo para a análise do referido contexto e manifestar nosso débito para com ele. Sejam quais forem suas limitações, Dunning estava correto ao se preocupar em ir além da descrição das particularidades do fenômeno da violência no futebol em cada região do mundo. Afinal, consideramos que, assim 
como não devemos universalizar suas análises do contexto britânico, não devemos perder de vista a possibilidade da existência de similitudes, pois elas podem estar relacionadas a mudanças culturais e sociais comuns e sublinhar a importância da troca de conhecimento para a formulação de políticas públicas.

\section{REFERÊNCIAS}

ALABARCES, Pablo. 'Aguante' and repression: football, politics and violence in Argentina. In: DUNNING, Eric; MURPHY, Patrick; WADDINGTON, Ivan ASRININAKIS, A. (Ed.) Fighting fans: football hooliganism as a world phenomenon. Dublin: University College Dublin, 2002. p. 23-36.

ALABARCES, Pablo. Crónicas del aguante: fútbol, violencia y política. Buenos Aires: Capital Intelectual, 2012.

ARAGÃO, Cristal Oliveira Moniz. Torcendo as torcidas: cartografias e representações sociais de torcedores no Rio de Janeiro. 200f. 2013. Tese (Doutorado em Psicologia Social). - Universidade Federal do Rio de Janeiro, 2013.

ARMSTRONG, Gary. Football hooligans: knowing the score. New York: Berg, 2013.

CANALE, Vitor dos Santos. Torcidas organizadas e seus jovens torcedores: diversidades e normativas do torcer. 2012. 119 f. Dissertação (Educação Física e Sociedade) - Faculdade de Educação Física, Universidade Estadual de Campinas, Campinas, 2012.

CARNEIRO, Henrique Figueiredo; SANTOS, Márcia Batista dos. A lei e a anomia nas torcidas organizadas de futebol. Arquivos Brasileiros de Psicologia, Rio de Janeiro, v. 60, n. 3, p. 104108, 2008.

CAVALCANTI, Zartú Giglio. Identidade coletiva de torcidas organizadas de futebol. 2002. 150 f. Tese (Doutorado em Psicologia Social) - Programa de Estudos Pós-Graduados em Psicologia Social, Pontifícia Universidade Católica de São Paulo, São Paulo, 2002.

COAKLEY, Jay; DUNNING, Eric. General Introduction. In: COAKLEY, Jay; DUNNING, Eric (Org.). Handbook of sport studies. London: Sage, 2000.

HARRÉ, Rom.; VAN LANGENHOVE, Luk. The dynamic of social episodes. In: HARRÉ, Rom; VAN LANGENHOVE, Luk. (Orgs.). Positioning theory: moral contexts of intentional actions. Oxford: Blackwell, 1999. p. 1-13.

DUNNING, Eric. El fenómeno deportivo: estudios sociológicos en torno al deporte, la violencia y la civilización. Barcelona: Paidotribo, 2003.

DUNNING, Eric. The social roots of football hooliganism: a reply to the critics of the 'Leicester School'. In: GIULIANOTTI, Richard; BONNEY, N.; HEPWORTH, M. (Ed.). Football, violence and social identity. London: Routledge, 2006. p. 128-157.

DUNNING, Eric. Sociologia do esporte e os processos civilizatórios. São Paulo: Annablume, 2014.

DUNNING, Eric; MURPHY, Patrick; WILLIAMS, John. Spectator violence at football matches: towards a sociological explanation. In: ELIAS, Norbert; DUNNING, Eric. Quest for excitement: sport and leisure in the civilizing process. Cambridge: Blackwell, 1993. p. 245-266. 
DUNNING, Eric et al. Towards a sociological understanding of football hooliganism as a world phenomenon. In: DUNNING, Eric; MURPHY, Patrick; WADDINGTON, Ivan; ASTRINAKIS, Antonios E. (Ed.) Fighting fans: football hooliganism as a world phenomenon. Dublin: University College Dublin, 2002.

ELIAS, Norbert; DUNNING, Eric. A busca da excitação. Lisboa, DIFEL, 1992.

GIULIANOTTI, Richard. Sociologia do futebol: dimensões históricas e socioculturais do esporte das multidões. São Paulo: Nova Alexandria, 2002.

HARRÉ, Rom; VAN LANGENHOVE, Luk. The dynamic of social episodes. In: HARRÉ, Rom; VAN LANGENHOVE, Luk (Org.). Positioning theory: moral contexts of intentional actions. Oxford: Blackwell, 1999. p. 1-13.

HRYNIEWICZ, Roberto Romeiro. Torcida de futebol: adesão, alienação e violência. 2008. 167 f. Dissertação (Mestrado em Psicologia Escolar) - Instituto de Psicologia, Universidade de São Paulo, São Paulo, 2008.

IBAÑEZ, Tomás. O "giro linguístico". In: IÑIGUEZ, Lupicinio. (Coord). Manual de análise do discurso em ciências sociais. 2 ed. Petrópolis: Vozes, 2005. p. 19-49.

HOLLANDA, Bernardo Borges Buarque de. 0 clube como vontade e representação: 0 jornalismo esportivo e a formação das torcidas organizadas de futebol do Rio de Janeiro (1967-1988). 2008. 771 f. Tese (Doutorado em História) - Departamento em História, Pontifícia Universidade Católica do Rio de Janeiro, Rio de Janeiro, 2008.

KLEIN, Marco Aurelio. Preservar o espetáculo garantindo a segurança e o direito à cidadania: relatório final da fase I da Comissão Paz no Esporte. Brasília: Brasília, DF: Ministério do Esporte e Ministério da Justiça, 2005/2006. Disponível em: <http://www.esporte.gov.brl arquivos/institucional/relatorioFinalPazEsporte.pdf>. Acesso em: 26 jan. 2012.

LOPES, Felipe Tavares Paes. Discursos sobre violência envolvendo torcedores de futebol: ideologia e crítica na construção de um problema social. 2012. 589f. Tese (Doutorado) - Curso de Psicologia, Instituto de Psicologia, USP, São Paulo, 2012.

LOPES, Felipe Tavares Paes. Dimensões ideológicas do debate público acerca da violência no futebol brasileiro. Revista Brasileira de Educação Física e Esporte, São Paulo, v. 27, n. 4, p. 597-612, out/dez. 2013.

LOPES, Felipe Tavares Paes; CORDEIRO, Mariana Prioli. Torcidas organizadas do futebol brasileiro: singularidades e semelhanças com outros grupos de torcedores da América do Sul e da Europa. Revista Espaço Acadêmico, Maringá, n. 104, p. 75-83, jan. 2010.

LUCCAS, Alexandre Nicolau. Futebol e torcidas: um estudo psicanalítico sobre o vínculo social. 1998. 166 f. Dissertação (Mestrado em Psicologia Social) - Programa de Estudos PósGraduados em Psicologia Social, Pontifícia Universidade Católica de São Paulo, São Paulo, 1998.

MONTEIRO, Rodrigo de Araujo. Torcer, lutar, ao inimigo massacrar: Raça Rubro-Negra! Uma etnografia sobre futebol, masculinidade e violência. Rio de Janeiro: FGV, 2003.

MOREIRA, Verónica. "Así cualquiera tiene aguante, de fierro tiene aguante todo el mundo". Disputas morales sobre las prácticas violentas en el fútbol. In: ZUCAL, José Garriga. Violencia en el fútbol: investigaciones sociales y fracasos políticos. Buenos Aires: Godot, 2013. p. 41-68. 
MURAD, Mauricio. A violência e o futebol: dos estudos clássicos aos dias de hoje. Rio de Janeiro: FGV, 2007.

MURAD, Mauricio. Para entender a violência no futebol. São Paulo: Saraiva, 2012.

MURPHY, Patrick; WILLIANS, John; DUNNING, Eric. 0 futebol no banco dos réus. Oeiras: Celta, 1994.

MURPHY, Patrick; SHEARD, Ken; WADDINGTON, Ivan. Figurational sociology and its application to Sport. In: COAKLEY, Jay; DUNNING, Eric. (Org.). Handbook of sport studies. London: Sage, 2000.

NETTO, Alfredo Euclides Dias. A violência nos estádios de futebol na perspectiva dos policiais militares de Curitiba: um estudo de caso. 2009. 199f. Dissertação (Mestrado em Ciências Sociais Aplicadas) - Programa de Pós-Graduação em Ciências Sociais Aplicadas da Universidade Estadual de Ponta de Grossa, Ponta Grossa, 2009.

PIMENTA, Carlos Alberto Máximo. Torcidas organizadas de futebol: violência e autoafirmação: aspectos da construção das novas relações sociais. Taubaté: Vogal, 1997.

REIS, Heloisa Helena Baldy dos. Futebol e sociedade: as manifestações da torcida. 1998. 164 f. Tese (Doutorado em Educação Física) - Faculdade de Educação Física, Universidade Estadual de Campinas, Campinas, 1998.

REIS, Heloisa Helena Baldy dos. Futebol e Violência. Campinas: Armazém do Ipê/Autores Associados/FAPESP, 2006.

SANTOS, Márcia Batista dos. Torcidas organizadas de futebol: um estudo sobre os impasses da lei em tempos de violência e anomia. 2009. 142 f. Dissertação (Mestrado em Psicologia) Centro de Ciências Humanas, Universidade de Fortaleza, Fortaleza, 2009.

SANTOS, Tarcyanie Cajueiro. Dos espetáculos de massa às torcidas organizadas: paixão, rito e magia no futebol. São Paulo: Annablume, 2004.

SUSTAS, Sebastián Ezequiel. Las violencias sentenciadas. Análisis de las leyes en torno a la seguridad deportiva en Argentina. In: ZUCAL, José Garriga. Violencia en el fútbol: investigaciones sociales y fracasos políticos. Buenos Aires: Godot, 2013. p. 351-374.

TEIXEIRA, Rosana da Câmara. Os perigos da paixão: visitando jovens torcidas cariocas. São Paulo: Annabulme, 2004.

TOLEDO, Luiz Henrique de. Torcidas organizadas de futebol. Campinas: Autores Associados: Campinas: Anpocs, 1996.

TOLEDO, Luiz Henrique de. Políticas da corporalidade: socialidade torcedora entre 1990-2010. In: HOLLANDA, Bernardo Borges Buarque de et al. A torcida brasileira. Rio de Janeiro: 7 Letras, 2012. p. 122-158.

TSOUKALA, Anastassia. Administrar a violência nos estádios da Europa: quais racionalidades? In: HOLLANDA, Bernardo Buarque de; REIS, Heloisa Helena Baldy dos. Hooliganismo e Copa de 2014. Rio de Janeiro: 7 Letras, 2014. p. 21-36.

VASILACHIS DE GIALDINO, Irene. El lenguaje de la violencia en los medios de comunicación. Las otras formas de ser de la violencia y de la prensa escrita. In: PROGRAMA DE LAS NACIONES UNIDAS PARA EL DESARROLLO. Aportes para la convivencia y la seguridad 
ciudadana. San Salvador: PNUD, 2004.

ZUCAL, José Garriga. "Soy Macho porque me la aguanto": etnografía de las prácticas violentas y la conformación de identidades de género masculinas. In: ALABARCES, Pablo.; CONDE, M. DODARO, C. (Comp.). Hinchadas. Buenos Aires: Prometeo Libros, 2006. p. 39-58.

ZUCAL, José Garriga. Nosotros nos peleamos: violencia e identidad de una hinchada de fútbol. Buenos Aires: Prometeu Libros, 2010. 